Article

\title{
Influence of Cultural Identity on Tourists' Authenticity Perception, Tourist Satisfaction, and Traveler Loyalty
}

\author{
Di Tian ${ }^{1}$, Qiongyao Wang ${ }^{1}$, Rob Law ${ }^{2}$ (I) and Mu Zhang ${ }^{1, *(1)}$ \\ 1 Shenzhen Tourism College, Jinan University, Shenzhen 518053, China; hnjytdd01@163.com (D.T.); \\ wang_qiongyao@163.com (Q.W.) \\ 2 School of Hotel and Tourism Management, The Hong Kong Polytechnic University, Hong Kong 999077, \\ China; rob.law@polyu.edu.hk \\ * Correspondence: zhangmu@jnu.edu.cn; Tel.: +86-75-5269-31865
}

Received: 1 June 2020; Accepted: 3 August 2020; Published: 6 August 2020

\begin{abstract}
Intangible cultural heritage is a natural fit for tourism development due to its extensive cultural and artistic value. Authenticity is important in the development of intangible cultural heritage tourism. This case study considered Celadon Town, a classic scenic spot of intangible cultural heritage in Zhejiang Province, China, to design questionnaires and a research model involving cultural identity, authenticity perception, tourist satisfaction, and traveler loyalty. This model was used to explore the indigenous presentation of authenticity, that is, the "Traditional Firing Technique of Longquan Celadon," and its impact on tourist satisfaction and loyalty. On the basis of the research model and hypotheses, relevant data were collected through a questionnaire survey, tested, and analyzed using a structural equation model (SEM). Findings indicate that authenticity of intangible cultural heritage has a significant positive effect on destination satisfaction and loyalty, which supplements related research on the authenticity of intangible cultural heritage destinations. This study advocates that building a characteristic town is a unique development mode of intangible cultural heritage tourism. The model integrates the cultural and tourism attributes of intangible cultural heritage. Based on this development model, the study offers related suggestions for the construction of authenticity and the realization of long-term development of tourism destinations.
\end{abstract}

Keywords: intangible cultural heritage tourism; cultural identity; authenticity perception; tourist satisfaction; loyalty

\section{Introduction}

In view of the recent boom in the global tourism industry, intangible cultural heritage has become an important tourism resource and attraction. Cultural heritage is a valuable asset that can support economic and cultural value [1]. Intangible cultural heritage should be protected when carrying out development due to its uniqueness and vulnerability. Traditional protection methods are categorized into five types, namely, salvage operation, folk protection, school education, museum preservation, and heritage institution [2], which can be combined with the process of tourism development. However, excessive tourism development will accelerate the demise of intangible cultural heritage and break its original inheritance system. Inadequate forms of tourism development will result in difficulties for products that are related to intangible cultural heritage to attract tourists. The lack of tourist endorsement on the development of intangible cultural heritage tourism can lead to limited value and waste of resources. Therefore, although intangible cultural heritage plays an important role in local tourism development, the abovementioned issues likewise require research attention, and tourism 
development requires comprehensive consideration. Consideration of not only the development of intangible cultural heritage itself, but also the feelings of tourists is thus necessary. As an important principle of cultural heritage tourism development, authenticity is also of great significance to the tourism development of intangible cultural heritage [3].

The purpose of this study was to investigate the influence of tourists' cultural identity on authenticity, tourist satisfaction, and traveler loyalty in the development of intangible cultural heritage. The paper is divided into five sections, comprising introduction, literature review, hypothesis establishment, empirical research, as well as discussion and conclusions. In the introduction, the main contents and basic structure of this research are described. The literature review clarifies the concepts and theories involved in this research. In the hypothesis establishment section, we put forward the related hypotheses of the study according to the research model. In the empirical research section, and based on primary data collected from a case study, we establish a structural equation model (SEM) and examine the relationship among cultural identity, authenticity perception, satisfaction, and tourist loyalty. In the discussion and conclusions section, we discuss and summarize the empirical results, and determine the means to take advantage of intangible cultural heritage to enhance local tourism. This study improves the framework and content of authenticity research, which can promote the initial development and construction of project resources and standardization of later operations. Findings can help maximize the contribution of authenticity research to local tourism, inheritance of conservation, and realization of sustainable development.

\section{Literature Review}

\subsection{Intangible Cultural Heritage Tourism and Cultural Identity}

This study aimed to solve practical problems in the development of tourism and intangible cultural heritage resources, as defined by the Intangible Cultural Heritage Law of the People's Republic of China [4]. Intangible cultural heritage refers to various traditional cultural expressions, physical objects, and places that have been passed down across generations and are regarded as integral to the lives of the people of a particular nation. This scope includes (1) traditional oral literature and language as the carrier; (2) traditional art, calligraphy, music, dance, drama, Quyi, and acrobatics; (3) traditional skills, medicine, and method for calculating days; (4) traditional etiquette, festivals, and other folk customs; (5) traditional sports and recreation; and (6) other intangible cultural heritage. Compared with materialized cultural heritage, intangible cultural heritage shows outstanding uniqueness. This uniqueness is mainly manifested in the external form and internal characteristics. In terms of external form, intangible cultural heritage has intangible characteristics and needs other physical carriers to be presented [5]. With respect to internal characteristics, the particularity of intangible cultural heritage is mainly manifested as living state. That is, the protection and inheritance of intangible cultural heritage needs to be realized by people's words and deeds [6]. These two characteristics should receive special attention when developing intangible cultural heritage.

Intangible cultural heritage tourism lacks an official definition, and relevant research in the Chinese context has emerged only after 2005. The studies at that time mainly focused on exploring the relationship between treating intangible cultural heritage as a form of tourist attraction within tourism development [7]. Moreover, such studies related to tourism development of intangible cultural heritage focused on the characteristics of tourism resources and development status [8]. Research studies closely related to the definition of tourism suggest that intangible cultural heritage is mainly used as a tourist attraction $[9,10]$, whereas other related activities are carried out on the premise of meeting specific needs of tourists [11]. Therefore, this study defines intangible cultural heritage tourism as people spending their leisure time to experience activities featuring intangible cultural heritage and its related products in a non-conventional environment, usually a tourist destination. The present study examined the development of such intangible cultural heritage and related tourism products from the perspective of tourists. After consulting relevant literature and research, cultural identity was 
taken as a pre-variable to measure the extent to which cultural identity influences tourist satisfaction and loyalty.

Cultural identity emphasizes the confirmation of a common culture among individuals and groups, which is related to their cultural background and atmosphere. The core of cultural identity is recognition and sense of value [12]. With the continuous development of the tourism industry, the study of cultural identity in the field of tourism has gained increasing attention. In the context of globalization, intangible cultural heritage tourism provides tourists with different sources of identity for destinations that enhance the role of cultural identity [13]. Various countries have used cultural tourism to create and strengthen national identity, as evidenced by festivals [14], religious tourism [15], and other activities. Cultural identity of intangible cultural heritage is defined as "the recognition of cultural value and identity", which reflects the relationship between people and the culture represented by such heritage [16]. In the development of intangible cultural heritage tourism, cultural identity refers to tourists' understanding and recognition of local culture in a non-conventional environment [17]. Therefore, cultural identity mentioned in this study refers to tourists' understanding and recognition of the cultural value displayed by the intangible cultural heritage of the destination. In the operation of measuring cultural identity, this study is based on the internal structure of cultural identity from the following three dimensions: cognitive, affective, and behavioral [18].

\subsection{Authenticity and Tourist Satisfaction}

With the emergence of cultural heritage tourism, authenticity has been attached to cultural and heritage tourism [19]. Authenticity has become a concept of heritage protection, which is closely related to the foundation of intangible cultural heritage. In the 1970s, MacCannell put forward objective authenticity, referring to tourism objects [20]. In the 1980s, Cohen proposed constructive authenticity that refers to that of tourism objects constructed by a society [21]. Eco raised the concept of postmodern authenticity, which suggests that no attention should be paid to the authenticity of an object and that no strict boundary should exist between true and false [22]. Wang developed existential authenticity on the basis of summarizing the concepts of authenticity in the analyses of objectivism, constructivism, and postmodernism [23]. Existential authenticity posited the real experience and self-cognition of tourism subjects, first put forward by Hughes and Daniel in 1995 and 1996, respectively [24]. It can be used to study the tourist activities for authenticity [25].

Intangible cultural heritage can be expressed in kind and also developed continuously. In research, authenticity is influenced by intangible and active characteristics and tends to incline toward constructivism and existentialism. Therefore, this study selected constructive and existential authenticity as the starting point to investigate the effects of tourists' perceived satisfaction and loyalty. Constructive authenticity pertains to tourist destinations, whereas existential authenticity focuses on tourists [23].

On the basis of traveler satisfaction, this study examined the mechanism of cultural identity and authentic perceptions of tourists in the development of intangible cultural heritage tourism. Customer satisfaction theory is an important aspect of consumer behavior theory, which, in turn, is rooted in service quality management. Research on customer satisfaction in tourism has mainly focused on connotation, formation, behavioral outcomes, satisfaction evaluation, and models [26]. Authenticity, as an influencing factor, has emerged with the rise and application of heritage tourism. For example, destination image plays a regulatory role in tourist satisfaction [27]. Therefore, this study presents a similar effort to measure the impact of authenticity as an influencing factor on intangible cultural heritage tourism and on tourist satisfaction.

In addition, in the study on behavioral outcomes, authenticity is typically combined with the tendency and loyalty of behavior to predict responses when discussing the impact of tourist opinions [28]. For example, traveler decisions on locations are mainly dependent on customer loyalty and include two major elements, namely, behavior and attitude [29]. However, most consumption is of a single instance and thus mainly measured by attitudinal loyalty, which is considered suitable 
for studying destination loyalty [30]. As such, intention to revisit and willingness to recommend are generally used as measurement indicators in related research [31,32]. Tourist satisfaction and destination loyalty are long-standing research topics, where satisfaction is widely used and empirically proven as the antecedent variable for predicting tourist loyalty. For example, satisfaction can be used as a mediating variable to influence loyalty $[33,34]$. However, the effect of satisfaction on revisiting and willingness to recommend may differ [35]. In addition, overall loyalty is also examined with satisfaction attributed and considered as a mediating variable [36]. Therefore, in a study of authenticity, highly mature levels of satisfaction and loyalty as variables of tourist behavior can effectively determine cultural heritage from the perspective of tourists. At the same time, the effect of authenticity on tourist behavior can also reveal insights into intangible cultural heritage.

\subsection{Theoretical Foundation}

This study examined the interrelationship among cultural identity, authentic perception, satisfaction, and tourist loyalty using the following theoretical basis.

(1) Authenticity Theory

Authenticity is a concept of protection in the field of cultural heritage. With the emergence of cultural heritage tourism, authenticity enters cultural research and emphasizes two characteristics, namely, "real" and "primitive". To date, authenticity theory is mainly based on the following points of view: objectivism, constructivism, postmodernism, and existentialism [23]. This study focused on constructive and existential authenticity.

(2) Customer Satisfaction Theory

Customer satisfaction theory elucidates the various factors in this study. Referring to the perceived extent to which customers' explicit, implicit, and obligatory needs or expectations have been met, customer satisfaction is the evaluation of product or service performance in providing a certain level of happiness. The level of satisfaction is a psychological experience, and customer satisfaction is a psychological evaluation of tourists after comparing pre-tourism expectations with post-tourism experiences [26].

(3) ABC Model of Attitudes

The ABC model of attitudes is a theory in consumer behavior research and an important theoretical basis for establishing the conceptual model of this study. $A B C$ is named after its three elements, as follows: Affect (A) refers to a consumer's perception toward attitudinal objects, Behavior (B) indicates a consumer's action intention towards certain attitudes, and Cognition (C) suggests a consumer's beliefs about attitudinal objects [37]. The model emphasizes the interrelationship among the three elements. The different levels of consumers' motivations lead to the relative importance of each element, in which the model's performance likewise differs. This study used the standard learning hierarchy in the $\mathrm{ABC}$ model of attitudes, where $\mathrm{C}$ takes the lead, followed by $\mathrm{A}$ and then $\mathrm{B}$ as an important theoretical reference.

\section{Hypothesis Development}

Cultural identity is the core mechanism for the sustainable development of intangible cultural heritage, in which people's cultural value recognition is an integral part [16]. Heritage identity refers to people's subjective heritage cognition, understanding, attitude, and evaluation [38]. Tourists' interest and motivation in a cultural site significantly affect the authentic experience of the destination, which is objective and existential [39]. The considerable identification of tourists with local culture leads to their deep understanding and consideration. In other words, if tourists gain further knowledge about tourist attractions, their perception about the authenticity of such attractions increases [40]. This study regarded cultural identity as an antecedent variable for tourists' perceptions of authenticity, and explored the effect of tourists' cultural identity in intangible cultural heritage tourism. According to the traditional relationship in terms of perceived value, tourist satisfaction, and destination loyalty, 
tourist satisfaction is frequently considered as a prerequisite for loyalty formation, which has likewise been shown to be the result of behavioral satisfaction [30]. Figure 1 shows the basic model of this study.

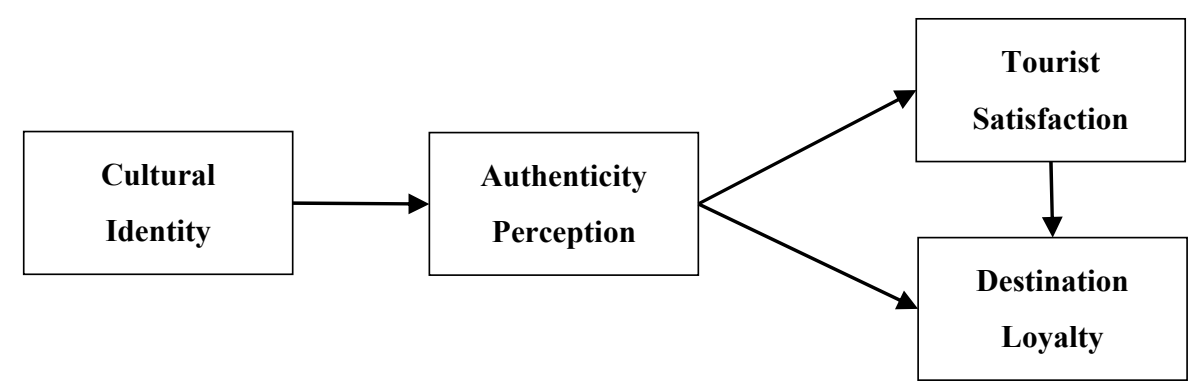

Figure 1. Basic model.

In the study of intangible cultural heritage tourism, the content for authenticity differs from that of other types of cultural heritage that are composed of constructive and existential authenticity. Constructive authenticity pertains to the contents of tourism objects and emphasizes the "authenticity" of tourist destinations or attractions as constructed by local residents. Existential authenticity is the content of a subject's feelings, which includes not only the real experience of a tourism object but also the real understanding of the tourist's self-identity. Thus, existential authenticity perception includes tourists' real experience of the "authentic" tourism object, which is constructed by a destination and is an important factor that influences tourists' personal experience and perception.

Authenticity perception is a well-known influencing factor in tourist satisfaction and has received increased research attention [41]. Satisfaction generally accompanies the relationship between loyalty and primacy perception. Authenticity perception can influence loyalty through the mediating role of satisfaction and can likewise directly influence loyalty [42,43].

The final conceptual model (Figure 2) and related hypothesis $(\mathrm{H})$ paths of this study are presented next.

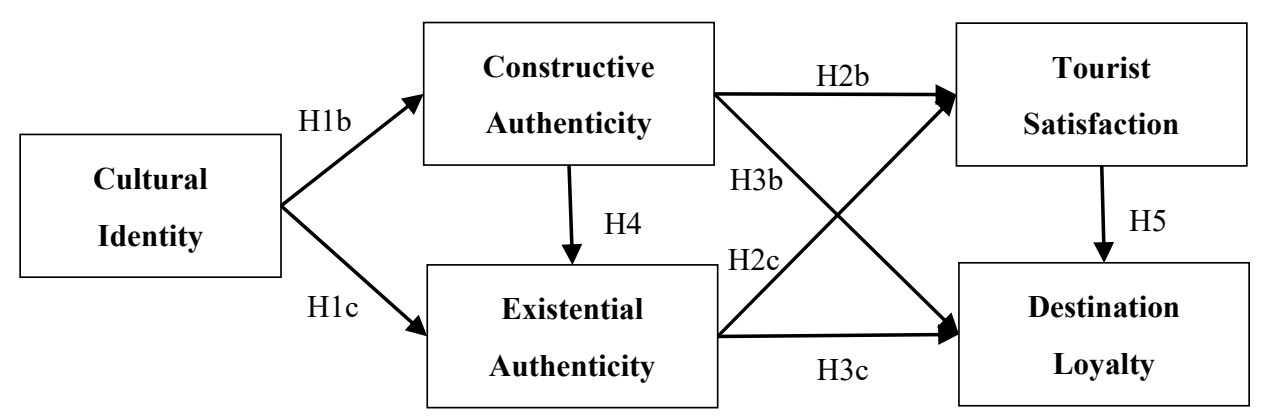

Figure 2. Conceptual research model on intangible cultural heritage tourism.

Hypothesis 1 (H1b). Cultural identity has a positive effect on constructive authenticity.

Hypothesis 1 (H1c). Cultural identity has a positive effect on existential authenticity.

Hypothesis 2 (H2b). Constructive authenticity perception has a positive effect on destination satisfaction.

Hypothesis $2 \mathbf{( H 2 c ) . ~ E x i s t e n t i a l ~ a u t h e n t i c i t y ~ p e r c e p t i o n ~ h a s ~ a ~ p o s i t i v e ~ e f f e c t ~ o n ~ d e s t i n a t i o n ~ s a t i s f a c t i o n . ~}$

Hypothesis 3 (H3b). Constructive authenticity perception has a positive effect on destination loyalty.

Hypothesis 3 (H3c). Existential authenticity perception has a positive effect on destination loyalty.

Hypothesis 4 (H4). Constructive authenticity perception has a positive effect on existential authenticity perception.

Hypothesis 5 (H5). Tourist satisfaction has a positive effect on destination loyalty. 


\section{Empirical Analysis}

\subsection{Case Survey}

This case study takes place in the Celadon Town of Longquan, Zhejiang Province, China, which is renowned for its traditional celadon firing techniques. The location was selected for three main reasons. (1) Celadon Town is China's only celadon-themed tourist attraction that is forward-looking and representative in the development of intangible cultural heritage tourism. (2) A preliminary understanding of the feasibility of this characteristic town in tourism development can be obtained through analysis. (3) The "Traditional Firing Skills of Longquan Celadon" is the only UNESCO-selected ceramic project, which represents the highest achievement of human ceramic civilization. Longquan Shangyu, the birthplace of modern Longquan celadon, has been an important place in the history of Chinese celadon culture. The local Piyun Celadon Cultural Park is a representative platform and window for the world to understand Longquan celadon culture. Figure 3 is a photo, showing the Celadon Town of Longquan.
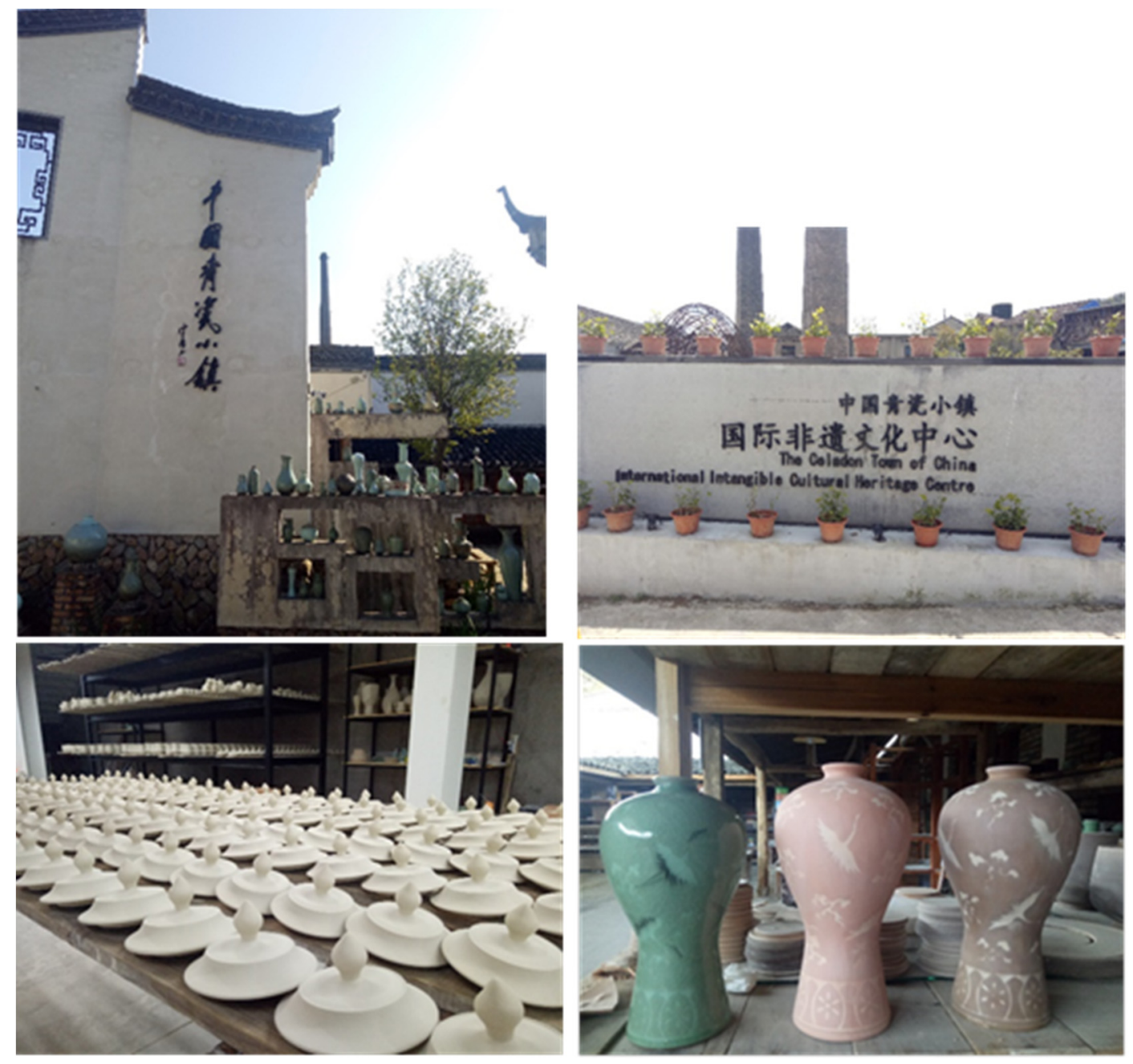

Figure 3. China's Celadon Town.

\subsection{Data Collection}

\subsubsection{Measurement Dimensions and Scale Design}

Based on the foregoing discussion, constructive and existential authenticities were selected as the research content for intangible cultural heritage tourism. Within the scope of the measurement 
dimension of cultural identity, Xin's research provides an effective measurement scale, which fits the thinking of this study. Therefore, this part mainly follows the research of Xin [44]. In determining related items, cultural identity was divided into three parts, namely, cognitive, affective, and evaluative behavioral [44]. Based on comprehensive field investigations and the literature summary, a total of 14 measurement items for cultural identity were determined, of which CI1-CI4 pertained to the cognitive dimension, $\mathrm{CI} 5-\mathrm{CI} 8$ denoted the affective dimension, and CI9-CI14 constituted the evaluative behavioral dimension (Table 1).

Table 1. Cultural identity measurement items and reference sources.

\begin{tabular}{|c|c|c|}
\hline $\begin{array}{c}\text { Measurement } \\
\text { Dimension }\end{array}$ & Measurement Item & $\begin{array}{c}\text { Main Reference } \\
\text { Source }\end{array}$ \\
\hline \multirow{3}{*}{$\begin{array}{l}\text { Cultural } \\
\text { Identity }\end{array}$} & $\begin{array}{l}\text { CI1 I think the residents of this destination are friendly. } \\
\text { CI2 I think the local history is fascinating. } \\
\text { CI3 I think the traditional culture is rich in content. } \\
\text { CI4 I have a good impression of the destination as a whole. }\end{array}$ & [44] \\
\hline & $\begin{array}{l}\text { CI5 I like the traditional culture of the destination. } \\
\text { CI6 I like the architectural style of the destination. } \\
\text { CI7 I like the cultural relics of the destination. } \\
\text { CI8 I like the intangible cultural heritage of the destination. }\end{array}$ & [44-46] \\
\hline & $\begin{array}{l}\text { C19 I want to know the dialect of the local residents. } \\
\text { CI10 I want to learn about the lifestyle of the destination residents. } \\
\text { CI11 I want to know about local customs. } \\
\text { CI12 I want to know about the representative traditional culture of the destination. } \\
\text { CI13 I want to know about the intangible cultural heritage of the destination. } \\
\text { CI14 I want to live in this destination. }\end{array}$ & {$[44,46]$} \\
\hline
\end{tabular}

The determination of authenticity-related measurement items was based mainly on the relevant research of Zhao, Zheng, and Yi et al. [47-49], together with comprehensive field investigation and literature summary content. A total of 22 measurement items were determined (Table 2), 12 of which fell under constructive authenticity (CA1-CA12) and 10 were under existential authenticity (EA1-EA10).

Table 2. Authenticity measurement items and reference sources.

\begin{tabular}{|c|c|c|}
\hline $\begin{array}{l}\text { Measurement } \\
\text { Dimension }\end{array}$ & Measurement Item & $\begin{array}{l}\text { Main Reference } \\
\text { Source }\end{array}$ \\
\hline \multirow{12}{*}{$\begin{array}{l}\text { Constructive } \\
\text { authenticity }\end{array}$} & CA1 The overall layout of the town is impressive. & \multirow{12}{*}[47,48]{} \\
\hline & CA2 The architectural style of the town is very cultural. & \\
\hline & CA3 The intangible cultural heritage tourism products in small towns have & \\
\hline & very cultural characteristics. & \\
\hline & $\begin{array}{l}\text { CA4 The crafts in small towns are very cultural. } \\
\text { CA5 The cultural relics displayed in the town are real. }\end{array}$ & \\
\hline & CA6 The town as a whole reflects strong regional cultural characteristics. & \\
\hline & CA7 The residents of the town maintain their original lifestyle. & \\
\hline & $\begin{array}{l}\text { CA8 The language of the residents of the town maintains its local } \\
\text { characteristics. }\end{array}$ & \\
\hline & CA9 The town's architecture maintains the local traditional features. & \\
\hline & CA10 The town's non-relics have maintained its traditional features. & \\
\hline & $\begin{array}{l}\text { CA11 The intangible experience activities in small towns have maintained } \\
\text { their traditional features. }\end{array}$ & \\
\hline & CA12 Related activities organized in small towns can help inherit the culture. & \\
\hline
\end{tabular}


Table 2. Cont.

\begin{tabular}{|c|c|c|}
\hline $\begin{array}{l}\text { Measurement } \\
\text { Dimension }\end{array}$ & Measurement Item & $\begin{array}{c}\text { Main Reference } \\
\text { Source }\end{array}$ \\
\hline $\begin{array}{l}\text { Existential } \\
\text { Authenticity }\end{array}$ & $\begin{array}{l}\text { EA1 This tour frees me from everyday life (work) and makes me feel free. } \\
\text { EA2 I feel that the intangible cultural heritage atmosphere is very strong. } \\
\text { EA3 I feel like I have integrated into the local intangible cultural heritage } \\
\text { culture. } \\
\text { EA4 This tour helped me learn more about non-relics. } \\
\text { EA5 I believe the local intangible cultural heritage experience activities are } \\
\text { very cultural. } \\
\text { EA6 The tour provided me with a unique cultural experience. } \\
\text { EA7 The tour triggered my thoughts on human civilization. } \\
\text { EA8 During the tour, I kept in touch with local people in a natural manner. } \\
\text { EA9 During the tour, I kept in touch with family members in an authentic } \\
\text { manner. } \\
\text { EA10 During the tour, I kept in touch with other tourists in a friendly manner. }\end{array}$ & {$[47,49]$} \\
\hline
\end{tabular}

In the measurement of destination satisfaction and loyalty, the former typically refers to achieving goals or meeting expectations, whereas the latter mainly includes two aspects, namely, behavior and attitude. In tourism research, attitudinal loyalty is often and likely observed and manifested in two dimensions, namely, revisit intention and recommendation intention. In the study and according to the literature summary, Table 3 determined three items of tourist satisfaction measurement (TS1-TS3) and four items of destination loyalty measurement (DL1-DL4).

Table 3. Tourist satisfaction and items of destination loyalty measurement with reference sources.

\begin{tabular}{|c|c|c|}
\hline $\begin{array}{l}\text { Measurement } \\
\text { Dimension }\end{array}$ & Measurement Item & $\begin{array}{c}\text { Main Reference } \\
\text { Source }\end{array}$ \\
\hline $\begin{array}{l}\text { Tourist } \\
\text { Satisfaction }\end{array}$ & $\begin{array}{l}\text { TS1 I have achieved my goal on this trip. } \\
\text { TS2 This tourist destination is similar to my ideal destination. } \\
\text { TS3 I am very satisfied with this tour. }\end{array}$ & {$[47,48]$} \\
\hline $\begin{array}{l}\text { Destination } \\
\text { Loyalty }\end{array}$ & $\begin{array}{l}\text { DL1 If I have the opportunity, I would like to revisit the destination. } \\
\text { DL2 I will recommend this destination to my friends. } \\
\text { DL3 In the future, I would like to go to similar tourist destinations. } \\
\text { DL4 I will recommend similar tourist destinations to my friends. }\end{array}$ & {$[42,44,49]$} \\
\hline
\end{tabular}

The research elaborated the dimensions of each variable in the conceptual model and its measurement items, as well as the core content of the questionnaire. The two variables of cultural identity and authenticity perception involve various items and the reference sources are partially unified. Thus, a pre-research was conducted and questionnaire items were deleted according to the analysis results to ensure the reliability and validity of the scale.

\subsubsection{Questionnaire Adjustment and Data Collection}

A pre-survey questionnaire was developed on the basis of the abovementioned measurement scale. The questionnaire was mainly divided into three parts. The first part collected basic participant information to understand the relationship between the respondents and the Chinese Celadon Town. The second part was the subject scale, which included cultural identity, authenticity perception, satisfaction, and loyalty. Likert-type scales were used to guide respondents in scoring various items in the questionnaire. A scale of 1 to 5 was used to indicate five options, namely, "totally disagree", "disagree", "uncertain", "agree", and "totally agree". These indicators were then measured for structural equation model analysis. The third part collected personal information from the respondents, which was used for group classification and comparative study.

To ensure the reliability and validity of the questionnaire, pre-investigation was required before the formal investigation. The pre-survey was carried out using convenience sampling in China's 
Celadon Town in November 2018. A total of 139 questionnaires were sent out, which were all collected. Eliminating duplicate answers or incomplete questionnaires yielded 130 valid questionnaires and recovery rate of $93.5 \%$. The pre-survey data were analyzed such that the questionnaire content could be adjusted to lay the foundation for a formal survey. In the adjustment process, Cronbach's $\alpha$ coefficients of the overall scale and each subscale were 0.887 and greater than 0.8 , respectively, which indicates the ideal internal reliability of the scale. Therefore, items were revised according to whether the total correlation coefficient was lower than the standard of 0.4. Three items (i.e., CI9, CI10, and CI14) in the cultural identity subscale were deleted and two items (i.e., CA7 and CA8) in the authenticity subscale were added. Finally, 38 measurement items were obtained, and the reliability of the final questionnaire was further improved.

Formal issuance of questionnaires was achieved through convenience sampling. In December 2018 and March 2019, formal and supplementary surveys were conducted in China's Celadon Town, respectively. Questionnaires were distributed in print and electronic formats. Respondents completed the print versions on the spot, and filled in the electronic versions through mobile phones. The latter was sent by users of third-party apps, such as MicroBlog and Ctrip (according to articles or comments to confirm that the respondent had visited China's Celadon Town), or by forwarding the survey through WeChat friends. On-site survey completion was conducted mainly in or around the scenic area of China's Celadon Town, Longquan passenger transport center, Longquan Celadon Museum, and other places. WeChat users who helped forward the questionnaire were mainly local residents and tourism practitioners in Longquan. A total of 427 questionnaires were distributed, of which 375 were considered valid. The questionnaire recovery rate was $87.8 \%$. In the SEM model, the ratio of the number of samples to the number of measurement items should be about 10:1, and the total number of samples should be controlled between 300 and 500 [50]. In this study, 43 items were used to construct the SEM model, and the final sample size was 375 items, which met the research requirements.

\subsection{Data Analysis}

\subsubsection{Descriptive Statistical Analysis}

The first part of the questionnaire focuses on information related to the Chinese Celadon Town to understand the number of tourists, their method of travel, purpose, and other information. The latter part focuses on demographic factors of the respondents to gather information on respondents' gender, age, educational level, origin, occupation, and income. Both parts are used for descriptive statistical analysis, as shown in Table 4.

Table 4. Descriptive statistics of sample basic information.

\begin{tabular}{llcc}
\hline & Sample Information & Frequency & Percentage (\%) \\
\hline \multirow{2}{*}{ Gender } & Male & 181 & 48.3 \\
& Female & 194 & 51.7 \\
\hline \multirow{5}{*}{ Age } & $<20$ & 30 & 8 \\
& $20-29$ & 83 & 22.1 \\
& $30-39$ & 125 & 33.3 \\
& $40-49$ & 56 & 14.9 \\
& $50-59$ & 71 & 18.9 \\
Educational Level & $\geq 60$ & 10 & 2.7 \\
& Elementary school or below & 0 & 0 \\
& Junior high school & 21 & 5.6 \\
& Technical secondary school or high school & 95 & 25.3 \\
& College or undergraduate & 251 & 66.9 \\
& Master degree or above & 8 & 2.1 \\
\hline
\end{tabular}


Table 4. Cont.

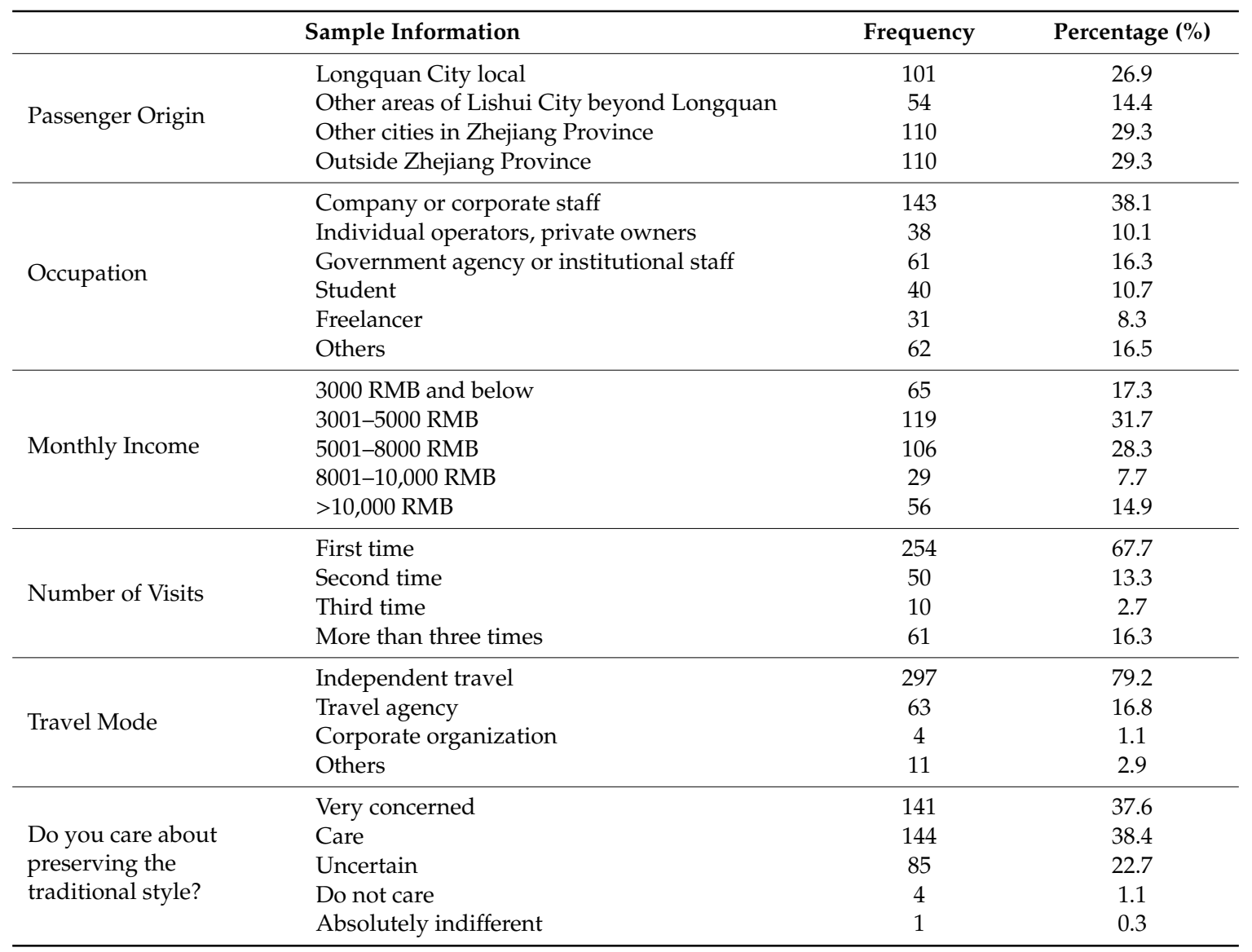

Table 4 shows a relatively balanced overall distribution of respondent characteristics, such as gender, age, occupation, and average monthly income. Most of the tourists have middle and high educational levels, and come from outside the city and province. Approximately $30 \%$ of tourists visit the Chinese Celadon Town more than once, which indicates the destination's current certain popularity and influence. In addition, tourists with the same cultural environment or high cultural recognition are willing to repeatedly visit Celadon. The survey also shows that $76 \%$ of the tourists care about the traditional style of the town, which indicates the influence of authenticity in the development of intangible cultural heritage tourism.

\subsubsection{Exploratory Factor Analysis}

The reliability analysis of the official survey data showed that Cronbach's $\alpha$ coefficient for each questionnaire was greater than 0.8 , which indicates good reliability. The exploratory factor analysis (EFA) of the data was then carried out using IBM SPSS Statistics 21.0. Table 5 presents the results. 
Table 5. Reliability analysis of scale.

\begin{tabular}{|c|c|c|c|c|c|}
\hline & Measuring Object & $\begin{array}{l}\text { Number } \\
\text { of Items }\end{array}$ & Factor $\alpha$ & Subscale $\alpha$ & Total $\alpha$ \\
\hline \multirow{3}{*}{$\begin{array}{l}\text { Cultural } \\
\text { Identity }\end{array}$} & Cultural cognition & 4 & 0.894 & \multirow{3}{*}{0.912} & \multirow{12}{*}{0.911} \\
\hline & Cultural emotion & 4 & 0.9 & & \\
\hline & Cultural behavioral intention & 3 & 0.882 & & \\
\hline \multirow{3}{*}{$\begin{array}{l}\text { Constructive } \\
\text { Authenticity }\end{array}$} & Environmental authenticity & 3 & 0.0834 & \multirow{3}{*}{0.887} & \\
\hline & Product authenticity & 4 & 0.867 & & \\
\hline & Active authenticity & 3 & 0.839 & & \\
\hline \multirow{3}{*}{$\begin{array}{l}\text { Existential } \\
\text { Authenticity }\end{array}$} & Self-worth authenticity & 3 & 0.861 & \multirow{3}{*}{0.901} & \\
\hline & Travel experience authenticity & 4 & 0.883 & & \\
\hline & Interpersonal communication authenticity & 3 & 0.864 & & \\
\hline Satisfaction & & 3 & & 0.824 & \\
\hline Loyalty & & 4 & & 0.840 & \\
\hline General Scale & & 38 & & & \\
\hline
\end{tabular}

\subsubsection{Confirmatory Factor Analysis}

EFA aims to identify the structure of the scale and establish the construct validity of the questionnaire. Conversely, confirmatory factor analysis (CFA) determines whether the factor structure model and corresponding analysis data are in agreement [50]. Based on the factor structure determined by EFA in the pre-survey, IBM SPSS Amos 23.0 was used to carry out CFA for the latent variables. Among them, cultural identity, constructive authenticity, and existential authenticity had distinct structural differences. Satisfaction and loyalty were two latent variables with a uniform internal structure and less observational variations. Thus, CFA was only applied to the first three variables. Second-order CFA was used because the first analysis indicated a moderate to high correlation in the first-order factor constructs. Thus, the factor analysis model could be adapted to the sample data [50].

According to $\mathrm{Wu}$, cultural identity is composed of three dimensions, namely, cultural cognition, cultural emotion, and cultural behavioral intention, comprising 11 items of measurement [50]. Construct authenticity comprises three dimensions, namely, environmental, product, and activity authenticities, including 10 measurement items. Existential authenticity has three dimensions, namely, self-worth, tourism experience, and authenticity of interpersonal communication, containing 10 measurement items. After CFA, the model constructed by the three latent variables displayed good intrinsic quality, and the measurement indicators effectively reflected the common factor concept.

\subsubsection{Structural Equation Model Analysis}

The proposed structural equation model (SEM) included structural and measurement models in which the former required the determination of the relationship between the latent and associated variables in advance. The structural model pertained to latent variables, which contained five elements, namely, cultural identity, constructive authenticity, existential authenticity, satisfaction, and loyalty. The relationship and role of each latent variable were marked for further verification. In SEM analysis, various latent variables can be used to measure items, such as cultural identity, constructive authenticity, and existential authenticity. The item can then be packaged into a new variable in the scale to reduce the structural equation complexity and to facilitate analysis [51]. Therefore, according to the factor analysis results of each relevant scale, the items for cultural identity, constructive authenticity, and existential authenticity were packaged as new variables in the SEM. Figure 4 displays the initial SEM, in which TS1-TS3 represent the measurement items of tourist satisfaction and DL1-DL4 represent the measurement items of destination loyalty. 


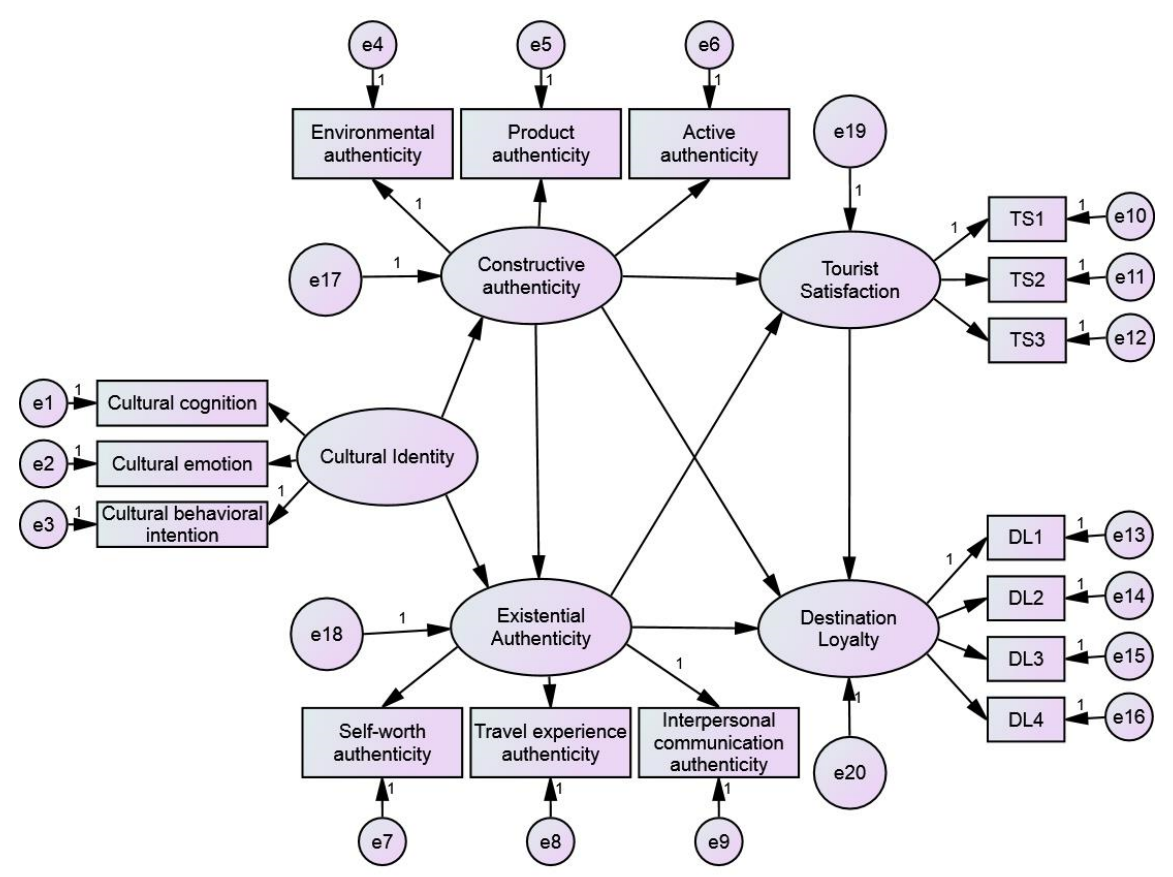

Figure 4. Initial model.

The IBM SPSS Amos 23.0 software calculated the fitness indexes of the model: the $\chi^{2} / \mathrm{df}$ value was 2.126, which is less than the standard value of 3. Values for Adjusted Goodness of Fit Index (AGFI), Goodness of Fit Index (GFI), Normed Fit Index (NFI), Tucker-Lewis Index (TLI), Incremental Fit Index (IFI), and Comparative Fit Index (CFI) met the standards of greater than 0.9. Standardized Root Mean Square Residual (SRMR) was 0.049, which is less than 0.05, whereas Root Mean Square Error of Approximation (RMSEA) was 0.055, which is less than 0.08. Therefore, each fitting index of the model met the general research criteria, and the model was considered to have a good fit.

The maximum likelihood method was used to estimate the parameters between the model variables. The hypothetical path "existential authenticity leads to loyalty" and "constructing authenticity to existential authenticity" showed no significant influence. To achieve a better model effect, deleting the two paths was considered to modify the model results. Two methods were employed for model modification, namely, modifying the path relationship between latent variables (i.e., deleting the non-significant path) and modifying the covariant relationship of residual terms. In general, updating the model prioritizes the path relationship between the modified latent variables, based on the principle of successive updating. That is, parameters were introduced one at a time, which sequentially resulted in deletion of the non-significant relationship paths "existential authenticity $\rightarrow$ loyalty" and "constructing authenticity $\rightarrow$ existential authenticity". The modified model fitness was tested, and the results are provided in Table 6. Compared with the initial model, the proposed model indicates little change and is at a relatively high level of adaptability. The model output and data matching are high, and the remaining hypothetical paths are valid.

On the basis of the final model output and the summary of model operation results, the study verified the research hypotheses and obtained the analysis results (Table 6). 
Table 6. Validation results of the research hypotheses.

\begin{tabular}{clc}
\hline Numbering & \multicolumn{1}{c}{ Hypothetical Description } & Test Results \\
\hline H1a & Cultural identity has a positive effect on authenticity perception. & Supported \\
$\mathrm{H} 1 \mathrm{~b}$ & Cultural identity has a positive effect on constructive authenticity. & Supported \\
$\mathrm{H} 1 \mathrm{c}$ & Cultural identity has a positive effect on existential authenticity. & Supported \\
$\mathrm{H} 2 \mathrm{a}$ & $\begin{array}{l}\text { Authenticity perception has a positive effect on destination } \\
\text { satisfaction. }\end{array}$ & Supported \\
$\mathrm{H} 2 \mathrm{~b}$ & $\begin{array}{l}\text { Constructive authenticity perception has a positive effect on } \\
\text { destination satisfaction. }\end{array}$ & Supported \\
$\mathrm{H} 2 \mathrm{c}$ & $\begin{array}{l}\text { Existential authenticity perception has a positive effect on } \\
\text { destination satisfaction. }\end{array}$ & Supported \\
$\mathrm{H} 3 \mathrm{a}$ & $\begin{array}{l}\text { Authenticity perception has a positive effect on destination loyalty. } \\
\text { Constructive authenticity perception has a positive effect on }\end{array}$ & Partially supported \\
$\mathrm{H} 3 \mathrm{~b}$ & $\begin{array}{l}\text { destination loyalty. } \\
\mathrm{H} 3 \mathrm{c}\end{array}$ & $\begin{array}{l}\text { Existential authenticity perception has a positive effect on } \\
\text { destination loyalty. }\end{array}$ \\
$\mathrm{H} 4$ & $\begin{array}{l}\text { Constructive authenticity perception has a positive effect on } \\
\text { existential authenticity perception. }\end{array}$ & Unsupported \\
$\mathrm{H} 5$ & Destination satisfaction has a positive effect on destination loyalty. & Unsupported \\
\end{tabular}

Figure 5 and Table 6 show that all hypotheses are supported except for H3c and H4. Cultural identity has a significant effect on authenticity perception, which positively influences tourist satisfaction; constructive authenticity perception has a significant effect on destination loyalty; existential authenticity indirectly affects loyalty through satisfaction; and tourist satisfaction has a positive effect on destination loyalty. The path coefficient in Figure 5 reflects the degree of influence. From the perspective of the path coefficient, the influence of cultural identity on constructive authenticity perception is comparable to that of existential authenticity perception, which has a slightly higher impact on tourist satisfaction than constructivism authenticity perception. This finding indicates that, in intangible cultural heritage tourism, cultural identity influences tourists' authentic perception of destination or attractions and their self-worth. Tourists' realization of self-worth, tourism experience, and interpersonal communication can play an active role in tourist satisfaction; a high satisfaction of tourists leads to a high level of loyalty. Apparently, objective tourist attractions are likewise crucial.

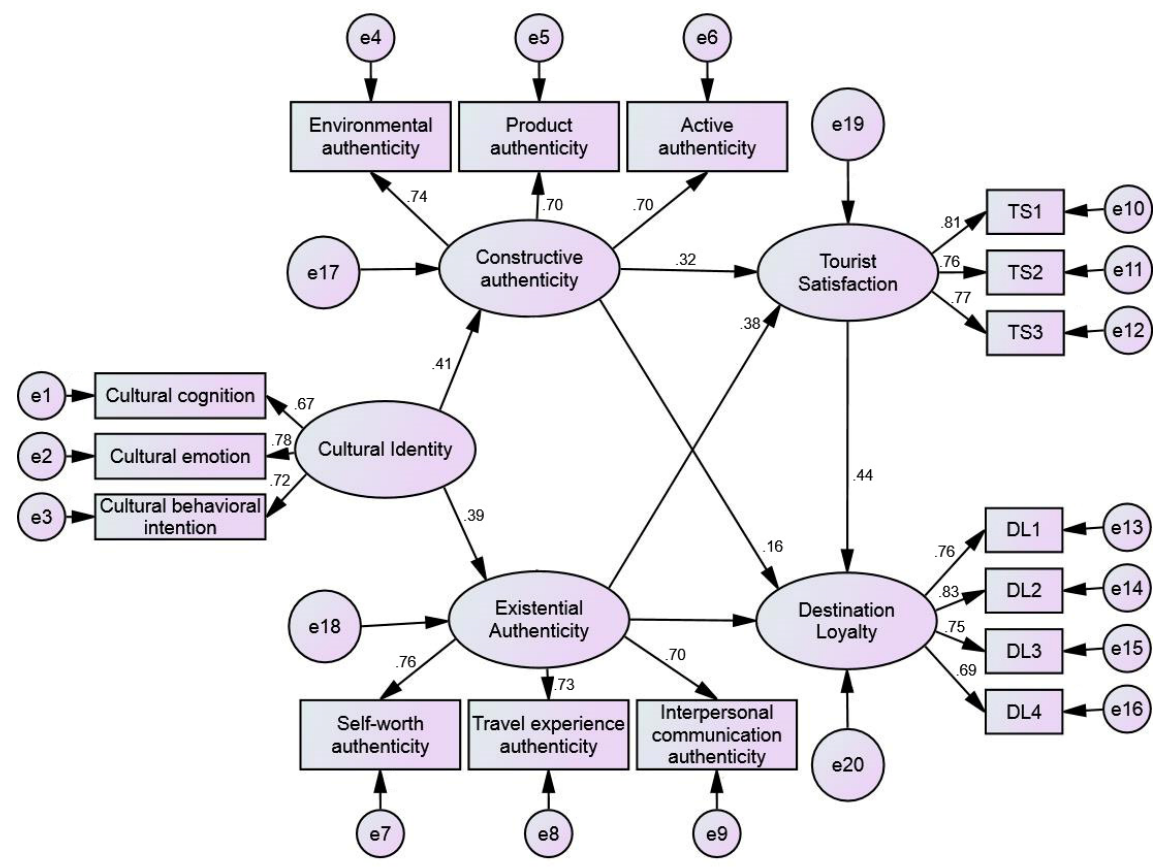

Figure 5. Final model output. 
In addition, analysis reveals that the three dimensions influencing cultural identity are mainly expressed in emotions, followed by cultural behavioral intention, and cultural cognition. Among the three aspects of authenticity construction, environmental authenticity is the most apparent, while product and active authenticities play a similar role. Among the three parts of existential authenticity, self-worth has the greatest influence, whereas interpersonal communication has the smallest influence. Therefore, when developing intangible cultural heritage tourism, tourist destinations should pay attention to the cultural and emotional connection between tourists and intangible cultural heritage. Based on this connection, destinations can create the authenticity of tourism environment and realize tourists' self-identity. In this way, the experience quality of tourists can be improved more effectively.

\section{Discussion and Conclusions}

\subsection{Discussion}

The results of this empirical research show that cultural identity has a significant positive impact on authenticity perception, including constructive authenticity, and existential authenticity. The perception of authenticity affects tourists' experience and behavior-existential authenticity only affects tourists' satisfaction experience, while constructive authenticity affects tourists' satisfaction and loyalty at the same time. Therefore, when developing intangible cultural heritage tourism, it is necessary to make good use of the relationship between tourists' cultural identity and authenticity perception, and give full attention to the promotion of tourists' satisfaction and destination loyalty.

As far as the study of cultural identity is concerned, there have been a limited number of studies on intangible cultural heritage. This study refers to the scale of cultural identity for tourism destination. Considering the characteristics of intangible cultural heritage, more work should be carried out to develop a cultural identity scale that is suitable for intangible cultural heritage in order to make relevant research more focused. In addition, we should pay attention to the research on the objective authenticity of intangible cultural heritage, develop an authenticity scale that is applicable to intangible cultural heritage, and enrich the relevant content of the authenticity.

According to the results of this study, tourists' perception of authenticity is really influenced by cultural identity in intangible cultural heritage tourism. This conclusion can be discussed in more details in the specific situation of the sample. It would be important to find the answers to these research questions: Will the sources of tourists affect their cultural identity? Will the way tourists travel affect their perception of local authenticity? Moreover, the relationship between cultural identity and authenticity perception confirms that the formation of authenticity perception can be influenced by other factors. So, apart from cultural identity, what are these additional factors? Therefore, further work should explore more possibilities and enrich related research.

\subsection{Conclusions}

On the basis of the literature review and theoretical foundation, this study builds a structural model of cultural identity, authenticity perception, satisfaction, and loyalty of tourists. Analysis of the relationship among these variables shows that cultural identity positively influences tourist perception, satisfaction, and loyalty to tourist destinations. In the dimension of cultural identity, the construction and existence of authenticity have a different influence on latent variables. Among the three dimensions of cultural identity and as far as influence is concerned, cultural emotion is a priority, followed by cultural behavior and cognition. Comparison of the three parts of authenticity construction presents the resulting order: environmental authenticity, product authenticity, and activity authenticity. Similarly, in different aspects of existential authenticity, self-worth is more important than travel experience, followed by interpersonal communication.

In view of its impact on tourist satisfaction, the feelings and experiences of travelers require special attention from the local government when committing to improving tourist satisfaction. In constructing 
authenticity, authorities should first maintain the normal working conditions of the local environment and gradually improve tourism-related products and activities, while helping tourists realize their self-worth for a better experience. In addition, a good experience can effectively promote desirable tourist behavior and loyalty to intangible cultural heritage tourism because tourist satisfaction positively influences loyalty to destinations.

\subsection{Implications}

Based on the above research and discussions, suggestions are provided for the development and operation of intangible cultural heritage tourism after taking China's Celadon Town as a case study. Corresponding destinations are expected to benefit from the same promotions.

(1) In the development of intangible cultural heritage tourism, travel organizations should highlight authenticity construction. The authenticity perception of intangible cultural heritage differs from tangible cultural heritage. However, its performance in objective authenticity is not prominent but manifested in constructive and existential authenticity. Results indicate that tourist authenticity perception positively affects satisfaction and loyalty, whereas constructing authenticity perception differs from creating existential authenticity. Constructing authenticity directly affects loyalty, whereas existential authenticity affects loyalty through satisfaction. Therefore, governments and operators should note the construction of tourism attractions and realization of tourists' self-worth at destinations. Most tourists are concerned about the overall traditional style of tourist destinations and experiences with intangible cultural heritage, which requires special attention to ensure unity of style in development and planning, with additional efforts to preserve the internal layout details, and maintain the consistency of the overall traditional style of the tourist destination in future development.

(2) For the development of intangible cultural heritage tourism, focus on the core needs of tourists should be increased. Helping visitors learn more about intangible cultural heritage by providing systematic knowledge content, additional leisure and entertainment items, and artistic value and various forms of celadon products can encourage re-visitation. Improving tourist satisfaction can be achieved through certain factors, such as improving cultural identity and enhancing tourist perceptions of authenticity. The management of intangible cultural heritage tourism should focus on improving tourist satisfaction to increase positive word-of-mouth publicity. The internal services of tourism destinations should be optimized according to the needs of tourists. Intangible cultural heritage and leisure tourism destinations should be combined to display the integration of cultural and tourism attributes of intangible cultural heritage, and highlight the core image of intangible cultural heritage tourism destinations to emphasize the publicity of the overall tourism image.

(3) The tourism development model of Celadon Town has important referential significance for the development of other destinations for intangible cultural heritage tourism. Longquan built this characteristic town by relying on celadon and its firing techniques. Through this model, the tourism-based development of local intangible cultural heritage was carried out, and Longquan created a novel tourism development for intangible cultural heritage. Tourism destinations of intangible cultural heritage not only integrate all aspects of intangible cultural heritage with the help of a characteristic town, but also bring such components together to enable a better play on their synergistic effects. This development model integrates the cultural aspect of intangible cultural heritage into tourism development, and improves its specific perception among tourists, which helps build the overall image of intangible cultural heritage and promotes the development of local tourism. 
Author Contributions: Conceptualization, M.Z.; Funding acquisition, M.Z.; Investigation, D.T. and Q.W.; Methodology, Q.W. and R.L.; Writing—original draft, D.T. and Q.W.; Writing—review and editing, D.T., R.L., and M.Z. All authors have read and agreed to the published version of the manuscript.

Funding: This research was funded by the National Social Science Foundation of China (Grant number 16AZD055).

Conflicts of Interest: The authors declare no conflict of interest.

\section{References}

1. Throsby, D. Economics and Culture; Cambridge Univesity Press: Cambridge, UK, 2001.

2. Liu, K. On the development relationship between tourism and intangible cultural heritage management. Chin. Coll. Econ. 2010, 12, 129.

3. Ma, Y. The principle of authenticity protection in the context of intangible cultural heritage. HL Chron. 2013, 13, 283-285.

4. Intangible Cultural Heritage Law of the People's Republic of China. 2011. Available online: http: //www.gov.cn/flfg/2011-02/25/content_1857449.htm (accessed on 5 August 2020).

5. Zhang, X. Particularity of oral history research of inheritors of intangible cultural heritage-A case study of chongqing filigree inlaid inheritor li changyi. J. News Res. 2016, 7, 12-13.

6. Wang, R. Study on the particularity of intangible cultural heritage in tourism development of ethnic villages-A case study of taoping qiangzhai in lixian county, sichuan province. GZ Soc. Sci. 2010, 11, 37-40.

7. Hu, S.; Kan, R.; Cao, S. Research on tourism development of intangible cultural heritage in yichang. Spec. Econ. Zone 2006, 9, 238-240.

8. Ji, W. A Research on the Tour Exploitation of Chinese Intangible Cultural Heritage. Master's Thesis, Central China Normal University, Wuhan, China, 2007.

9. Zhang, L. A review of the popular definitions and concepts of tourism in the world: A re-understanding of the nature of tourism. J. Tour. 2008, 23, 86-91.

10. Wang, Y. A new probe into the concept of "tourism": Discussing with professors xie yanjun and zhang lingyun. J. Tour. 2010, 25, 12-17.

11. Wang, L.; Lu, S. Knowledge map analysis of foreign non-material cultural heritage tourism. J. Huain. Tch. Colg. 2017, 19, 54-62.

12. Cui, X. Cultural identity and its roots. J. Beijing Norm. Univ. 2004, 184, 102-104.

13. González, M.V. Intangible heritage tourism and identity. Tour. Manag. 2008, 29, 807-810. [CrossRef]

14. Zhang, C.X.; Fong, L.H.N.; Li, S.; Ly, T.P. National identity and cultural festivals in postcolonial destinations. Tour. Manag. 2019, 73, 94-104. [CrossRef]

15. Över, D. Cultural tourism and complex histories: The armenian akhtamar church, the turkish state and national identity. Qual. Sociol. 2016, 39, 173-194. [CrossRef]

16. Wang, Y.; Hu, H. Cultural identity: Core mechanism for the sustainable development of intangible cultural heritage. Fujian Forum 2014, 10, 49-55.

17. Chen, C.; Lu, C. Identity: A new perspective in the study of tourism experience. J. Tour. 2011, 26, 37-42.

18. Chen, D.; Xie, H. A study on the cultural identity of haisi people in quanzhou. J. Fujian Agric. For. Univ. 2018, 21, 83-89.

19. Jamal, T.; Hill, S. Developing a framework for indicators of authenticity: The place and space of cultural and heritage tourism. Asia Pac. J. Tour. Res. 2004, 9, 353-372. [CrossRef]

20. MacCannell, D. Staged authenticity: Arrangements of social space in tourist settings. Am. J. Sociol. 1973, 79, 589-603. [CrossRef]

21. Cohen, E. Authenticity and commoditization in tourism. Ann. Tour. Res. 1988, 15, 371-386. [CrossRef]

22. Eco, U. Travels in Hyperreality; Harcourt Brace Jovanovich: San Diego, CA, USA, 1986.

23. Wang, N. Rethinking authenticity in tourism experience. Ann. Tour. Res. 1999, 26, 349-370. [CrossRef]

24. Liu, Y.; Pan, L.; Li, L.; Wang, F. International research characteristics and development context of tourism authenticity: Analysis of literature on ssci publications based on scientometrics method. Fgn. Econ. Manag. 2015, 37, 84-96. 
25. Steiner, C.J.; Reisinger, Y. Understanding existential authenticity. Ann. Tour. Res. 2006, 33, 299-318. [CrossRef]

26. Wang, X.; Liu, Z.; Zhang, H. A review and prospect of tourist satisfaction research. J. Beijing Sec. Fgn. Lang. Univ. 2010, 32, 22-29.

27. Lu, L.; Chi, C.G.; Liu, Y. Authenticity, involvement, and image: Evaluating tourist experiences at historic districts. Tour. Manag. 2015, 50, 85-96. [CrossRef]

28. Chen, C.F.; Chen, F.S. Experience quality, perceived value, satisfaction and behavioral intentions for heritage tourists. Tour. Manag. 2010, 31, 29-35. [CrossRef]

29. Wu, Y. A Study on the Relationship Among Customer Participation, Trust and Loyalty in Lhasa Folk Tourism. Master's Thesis, Southwestern University of Finance and Economics, Chengdu, China, 2013.

30. Chen, J.S.; Gursoy, D. An investigation of tourists' destination loyalty and preferences. Int. J. Contemp. Hosp. Manag. 2001, 13, 79-85. [CrossRef]

31. Jia, Y.; Lin, D. The impact of destination quality on tourist satisfaction and loyalty: The mediating role of local attachment and the moderating role of gender. Tour. Sci. 2017, 31, 65-78.

32. Akhoondnejad, A. Tourist loyalty to a local cultural event: The case of turkmen handicrafts festival. Tour. Manag. 2016, 52, 468-477. [CrossRef]

33. Ramseook-Munhurrun, P.; Seebaluck, V.N.; Naidoo, P. Examining the structural relationships of destination image, perceived value, tourist satisfaction and loyalty: Case of mauritius. Procedia Soc. Behav. Sci. 2015, 175, 252-259. [CrossRef]

34. Liu, Y.; Mao, D. A study on the influence of brand identity on tourist loyalty in red tourism destination: Taking tourist satisfaction as a mediator. Tour. Res. 2018, 10, 37-46.

35. Hutchinson, J.; Lai, F.; Wang, Y. Understanding the relationships of quality, value, equity, satisfaction, and behavioral intentions among golf travelers. Tour. Manag. 2009, 30, 298-308. [CrossRef]

36. Xia, L.; Yu, H. The influence of wetland park attributes and satisfaction on tourist loyalty: A case study of five wetland parks in harbin. J. Wetl. Sci. 2017, 15, 396-403.

37. Li, Q.; Wang, L. Research on consumers' repeated purchase intention based on abc attitude model. Cmcl. Res. 2016, 11, 17-23.

38. Zhang, C.; Qu, X.; Jin, Y. Heritage identity: Concept, connotation and research path. Hum. Geo. 2018, 33, $20-25$.

39. Kolar, T.; Zabkar, V. A consumer-based model of authenticity: An oxymoron or the foundation of cultural heritage marketing? Tour. Manag. 2010, 3, 652-664. [CrossRef]

40. Chhabra, D.; Healy, R.; Sills, E. Staged authenticity and heritage tourism. Ann. Tour. Res. 2003, 30, 702-719. [CrossRef]

41. Zhang, T.; Li, X.; Wen, H. Study on the impact of folk festival authenticity on tourism experience. J. Arid Land Resour. Environ. 2019, 33, 192-197.

42. Yu, Y.; Gong, J.; Zhang, C. The impact of tourists' authenticity perception on satisfaction and loyalty-Based on empirical research in enshi prefecture, hubei province. Econ. Geo. 2017, 37, 219-224.

43. Yu, Y.; Zhang, C.; Zeng, J.; Luo, J. Examining the structural relationships of authenticity perception place attachment and destination loyalty: An empirical study of enshi prefecture in hubei. Hum. Geo. 2017, 32, 145-151.

44. Xin, J. A Study on the Conceptual Model and Its Driving Factors of Cultural Heritage Tourism Based on Consumer Perspective. Master's Thesis, Tianjin University, Tianjin, China, 2016.

45. Santos, C.A.; Buzinde, C. Politics of identity and space: Representational dynamics. J. Travel Res. 2007, 45, 322-332. [CrossRef]

46. Lei, R.; Zhu, X.; Zhu, D. The development of regional cultural tourism industry from the perspective of identity experience: Based on the study of "huihang ancient road". J. Zhejiang Wanli Univ. 2015, 28, 18-23.

47. Zhao, Y. A Study on the Relationship between Authenticity Perception and Loyalty of Intangible Cultural Heritage Theme Park Visitors. Master's Thesis, Hunan Normal University, Changsha, China, 2017.

48. Zheng, H. Research on the Influence of Tourism Authenticity Perception on Tourists' Behavior Intention. Master's Thesis, Hunan Normal University, Changsha, China, 2018. 
49. Yi, X.; Fu, X.; Yu, L.; Jiang, L. Authenticity and loyalty at heritage sites: The moderation effect of postmodern authenticity. Tour. Manag. 2018, 67,411-424. [CrossRef]

50. Wu, M. Structural Equation Model: Amos Operation and Application; Chongqing University Press: Chongqing, China, 2010.

51. Wu, Y.; Wen, Z. Topic packaging strategy in structural equation modeling. Adv. Psychol. Sci. 2011, 19, 1859-1867.

(C) (1)

(C) 2020 by the authors. Licensee MDPI, Basel, Switzerland. This article is an open access article distributed under the terms and conditions of the Creative Commons Attribution (CC BY) license (http://creativecommons.org/licenses/by/4.0/). 